\title{
EL DERECHO A LA ASISTENCIA PÚBLICA EN LAS CONSTITUCIONES FRANCESAS DE 1791 Y 1793
}

\section{THE RIGHT TO PUBLIC ASSISTANCE IN THE FRENCH CONSTITUTIONS OF 1791 AND 1793}

\author{
Pablo Scotto \\ Universidad de Barcelona
}

\begin{abstract}
SUMARIO: I. DE LA DECLARACIÓN DE DERECHOS DE 1789 A LA CONSTITUCIÓN DE 1791.- 1.1. La oposición inicial a la Declaración.- 1.2. Los proyectos de Declaración.- 1.3. El Comité para la extinción de la mendicidad.1.4. El Plan de trabajo del Comité.- 1.5. El Primer Informe.- 1.6. El Cuarto Informe.- 1.7. La Constitución de 1791.- II. EN TORNO A LA CONSTITUCIÓN DE 1793.- 2.1. Nuevos proyectos de Declaración.- 2.2. El proyecto de Robespierre.2.3. La Constitución de 1793.- III. CONCLUSIÓN: LIBERTAD DE TRABAJO Y DERECHO A LA ASISTENCIA.
\end{abstract}

Resumen: Las Constituciones de 1791 y 1793 conciben la asistencia pública como una ayuda focalizada en los ciudadanos caídos en desgracia, sean válidos o inválidos. Ambos textos constitucionales son ambiguos con respecto a la amplitud de la asistencia que merecen los pobres válidos sin trabajo. Esta resulta inseparable de la nueva importancia que se asigna en la época a la libertad de trabajo. En primer lugar, los individuos tienen el derecho-deber de ganarse la vida a través del trabajo. Solamente en caso de constatada necesidad tienen derecho a la asistencia pública, acompañada, de nuevo, del deber de trabajar. Frente a esta combinación de libertad para competir y asistencia a los necesitados, surge un discurso revolucionario que antepone la garantía del derecho universal a la existencia a las acumulaciones de propiedad.

Abstract: The Constitutions of 1791 and 1793 understand public assistance as aid focused on fallen citizens, whether able-bodied or disabled. Both constitutional texts are ambiguous about the extent of the assistance the ablebodied unemployed deserve. This assistance is inseparable from the new importance given to freedom to work at that time. First of all, individuals have the right and the duty to earn a living through work. Only in case of proven need do they have the right to public assistance, again coupled with the duty to work. Facing this combination of freedom to compete and assistance to the needy, there arises a revolutionary discourse that places the guarantee of the universal right to existence before the accumulations of property.

Palabras clave: asistencia pública, libertad de trabajo, deber de trabajar, Revolución Francesa, derechos del hombre y del ciudadano, derecho a la existencia.

Key Words: public assistance, freedom to work, duty to work, French Revolution, rights of man and of the citizen, right to existence. 


\section{DE LA DECLARACIÓN DE DERECHOS DE 1789 A LA CONSTITUCIÓN DE 1791}

\subsection{La oposición inicial a la Declaración}

Desde finales de julio de 1789 , en la recientemente constituida Asamblea nacional, se desarrolla un intenso debate en Francia acerca de la conveniencia o no de redactar de forma inmediata una Declaración de derechos, destinada a encabezar la futura Constitución. Uno de sus detractores más destacados es Pierre-Victor Malouët, gran terrateniente en Santo Domingo. El 2 de agosto, oponiéndose a Boniface de Castellane y Antoine Pierre Barnave, pronuncia un discurso contra su adopción. El restablecimiento del orden público y la reforma de las finanzas del Estado, afirma, son cuestiones más urgentes que las "discusiones metafisicas". No niega que las leyes sean el resultado y la expresión de los derechos y deberes naturales, pero opina que no conviene declararlos antes de que sean modificados y limitados por las normas sociales. En definitiva: se opone a declarar de forma absoluta los principios del Derecho natural sin el contrapunto del Derecho positivo, que será fijado en la futura Constitución.

Sé que los americanos no tomaron esta precaución; cogieron al hombre del seno de la Naturaleza y lo presentaron al Universo en su soberanía primitiva. Pero la sociedad americana, formada recientemente, está compuesta en su totalidad por propietarios ya acostumbrados a la igualdad, ajenos tanto al lujo como a la indigencia, apenas conscientes del yugo de los impuestos y de los prejuicios que nos dominan, sin haber encontrado en la tierra que cultivan rastro alguno de feudalismo. ${ }^{1}$

Los Estados Unidos de América son una sociedad de propietarios, pero Francia está dividida entre siervos y señores. Si se tiene en cuenta esta desigualdad de fortunas y de estatus, es peligroso proclamar los derechos naturales del hombre antes de haber establecido cuáles son sus limites. Es una proclamación que tendría que ser enmendada, después, por la futura Constitución, y que por lo tanto es mejor dejar en suspenso por el momento. Hacer lo contrario, dice Malouët, sería tanto como engañar al siervo:

¿Por qué empezar transportándolo a una alta montaña, y mostrarle desde allí su imperio sin límites, si después tendrá que bajar para encontrarse trabas a cada paso?2

Al día siguiente, Malouët vuelve a hablar ante la Asamblea. Ante la crisis del comercio y de la industria, afirma, es necesario que el Estado asuma un nuevo gasto, favoreciendo la creación de "oficinas de asistencia y de trabajo" (bureaux de secours et de travail). ${ }^{3}$ Ligar la asistencia pública al trabajo, argumenta, tiene la

1 Pierre-Victor Malouët, Opinion de M. Malouët sur la Déclaration des Droits de l'Homme, dans la Séance du 2 Août, sin editorial ni lugar de edición, 1789, pp. 4-5.

2 Pierre-Victor Malouët, Opinion de M. Malouët sur la Déclaration des Droits de l'Homme, op. cit., p. 7. Pronto se empezará a hablar de esa alta montaña como el nuevo Monte Sinaí, y de los derechos del hombre como los nuevos Diez Mandamientos. Durante una fase posterior de la Revolución, en la que el parlamento pasará a llamarse Convención nacional, aquellos diputados que ocupan los asientos más elevados, y que se tienen a sí mismos como los defensores más consecuentes de los derechos naturales proclamados en el 89, serán conocidos precisamente como los montagnards.

3 Véase: Pierre-Victor Malouët, "Motion d'ordre de M. Malouët pour la création de bureaux de secours, lors de la séance du 3 août 1789", en Archives Parlementaires de 1787 à 1860 - Première série (1787-1799) Tome VIII : du 5 mai 1789 au 15 septembre 1789, P. Dupont, París, 1875 , p. 339. 
ventaja de que el gasto del Estado se vuelve productivo, al tiempo que se cumple con el deber sagrado de ayudar a los pobres.

Estas oficinas de trabajo están dirigidas a las gens de bras, a aquellos que ocupan el escalafón más bajo de la sociedad, y que propiamente no forman parte del tercer estado. ${ }^{4}$ La ayuda a esta clase al borde de la indigencia viene acompañada de medidas represivas, hasta el punto de que ambas cosas resultan inseparables:

Todos aquellos que no consten en el registro de alguna parroquia, y sean sorprendidos sin pasaporte, serán arrestados como vagabundos; se formarán brigadas a disposición de los empresarios encargados de la construcción de los grandes caminos. 5

Resumamos lo dicho hasta ahora. Justo después de argumentar en contra de la necesidad de una Declaración de derechos, Malouët pone sobre la mesa el que considera que es uno de los problemas más acuciantes del reino: el aumento de los pobres válidos sin trabajo. Aboga por establecer oficinas de asistencia y trabajo para socorrerlos, que en su propuesta no se distinguen claramente de las condenas a trabajos forzados. Como enseguida veremos, Malouët no tiene éxito en ninguna de sus dos pretensiones: la Declaración se aprueba, y el establecimiento de las oficinas de asistencia se deja para más adelante.

\subsection{Los proyectos de Declaración}

Entre finales de julio y mediados de agosto se presentan ante la Asamblea diversos proyectos de Declaración de derechos. Aunque formulada en otros términos, esa idea de Malouët de establecer oficinas de asistencia y de trabajo para los desocupados aparece en algunos de ellos. En el propuesto por Jérôme Pétion de Villeneuve, diputado por Chartres, puede leerse lo siguiente (artículo octavo):

Todo ciudadano debe tener una existencia asegurada, ya sea gracias a la renta de sus propiedades, ya sea a través de su trabajo y su industria; y si minusvalías o desgracias lo redujeran a la miseria, la sociedad debe proveerle su subsistencia. ${ }^{6}$

A primera vista, este texto podría interpretarse como una primera formulación del "derecho a la existencia", del que luego nos ocuparemos. Pétion estaría proponiendo asegurar este derecho a través de las instituciones públicas, proveyendo propiedades o trabajo a todos los ciudadanos. Pero el texto puede

\footnotetext{
4 En la sociedad francesa de finales del XVIII existe una marcada división social entre las gens de métier y las gens de bras. El trabajo de las "gentes de oficio", aunque inferior al de las artes nobles -en las que el intelecto pesa más que la mano-, es asimismo claramente distinto del trabajo de las "gentes de brazos". Estos trabajadores no cualificados, llamados a veces hommes de peine, quedan al margen del orden corporativo. Son, igual que los mendigos, las prostitutas, los vagabundos y los pequeños delincuentes, hombres y mujeres sans état. Véase: William H. Sewell, Jr., Trabajo y revolución en Francia. El lenguaje del movimiento obrero desde el Antiguo Régimen hasta 1848, Taurus, Madrid, 1992, pp. 37-68.

5 Pierre-Victor Malouët, "Motion d'ordre de M. Malouët pour la création de bureaux de secours", op. cit., p. 339.

6 Christine Fauré, Las declaraciones de los derechos del hombre de 1789, Fondo de Cultura Económica, Ciudad de México, 1995, p. 79.
} 
leerse también de otra manera. Según esta segunda interpretación, el artículo estaría dividido en dos partes. En la primera, Pétion simplemente recordaría que no puede ser un ciudadano libre aquel que no tiene una existencia asegurada, puesto que esta carencia le hace depender de otros en su vida cotidiana: solo puede ser miembro de la comunidad politica aquel que, gracias a sus propiedades o su trabajo, puede vivir de forma desahogada. Si bien este principio se formula aquí con un "debe", no estariamos ante un juicio normativo, sino condicional: gozar de una existencia material asegurada es una condición necesaria (o un requisito) para ser titular de los derechos de ciudadanía. El deber de la sociedad aparecería formulado únicamente en la segunda parte del artículo, pero ya no estaría dirigido a todos los ciudadanos, sino solamente a aquellos caídos en desgracia. El objetivo, además, no sería garantizarles una existencia digna, equiparable a la de aquellos que tienen propiedades o trabajan por sí mismos, sino únicamente permitirles subsistir.

Un diputado por París, Guy-Jean-Baptiste Target, propone un "Projet de Déclaration des droits de l'homme en société" que incluye este artículo sexto:

El Cuerpo Político debe a cada hombre los medios de subsistencia, ya sea

a través de la propiedad, del trabajo o de la asistencia [secours] de sus semejantes. 7

Este artículo, por su brevedad, es incluso más difícil de descifrar que el anterior, pero sabiendo de quién proviene todo indica que debemos optar por la interpretación más restrictiva: propiedad o trabajo como medios privados de ganarse el sustento necesario para ser ciudadano, asistencia como medio público para socorrer a aquellos que han caído en desgracia.

E1 20 y 21 de julio de 1789, el abate Sieyes presenta su proyecto de Declaración de derechos, titulado "Préliminaire de la Constitution. Reconnoissance et exposition raisonnée des droits de l'homme et du citoyen". Lo que distingue a esta exposición razonada de las anteriores propuestas es que establece no ya el deber de la sociedad de asistir, sino el derecho a la asistencia (artículo 25):

Todo ciudadano que se encuentre en la imposibilidad de ocuparse de sus necesidades tiene derecho a la asistencia [secours] de sus conciudadanos. ${ }^{8}$

En una versión revisada del primer proyecto, que Sieyes publica el 22 de julio, así como en su segundo proyecto, que data del 12 de agosto, figura también este derecho a la asistencia (artículo 27, en ambos textos):

Todo ciudadano que se encuentre en la imposibilidad de ocuparse de sus necesidades, o que se encuentre sin trabajo, tiene derecho a la asistencia [secours] de la sociedad, sometiéndose a sus órdenes. ${ }^{9}$

7 Guy-Jean-Baptiste Target, Projet De Déclaration des Droits de l'Homme en Societé, Baudouin, Paris, 1789, p. 2.

8 Emmanuel-Joseph Sieyes, Écrits politiques, edición y presentación de Roberto Zapperi, Éditions des Archives Contemporaines, Bruselas, 1985, p. 205.

9 Primer proyecto revisado: Emmanuel-Joseph Sieyes, Préliminaire de la Constitution françoise. Reconnoissance et exposition raisonnée des Droits de l'Homme et du Citoyen, Baudouin, Paris, 1789, p. 47. Segundo proyecto: Lucien Jaume (ed.), Les Déclarations des droits de l'homme. (Du Débat 1789-1793 au Préambule de 1946), con prefacio y notas del editor, Flammarion, París, 1989 , p. 128. 
Se pueden apreciar dos variaciones con respecto a la primera versión. Sieyes precisa que el derecho a la asistencia no solo lo poseen los inválidos, sino también los pobres válidos que no pueden procurarse trabajo por sí mismos. Ahora bien, y esta es la segunda precisión, este derecho a ser ayudados está condicionado a que los rescatados se sometan a las condiciones que la sociedad establezca. No cabe duda de que el abate está pensando especialmente en los pobres válidos, y que esas exigencias tienen que ver fundamentalmente con el deber de trabajar. Volveremos sobre esto más adelante.

De entre los proyectos presentados en el verano de 1789, el de Jean-Paul Marat es el único que plantea algo similar a lo que unos años después será llamado "derecho a la existencia". Escribe, en su "Projet de déclaration des droits de l'homme et du citoyen, suivi d'un Plan de constitution juste, sage et libre":

En un Estado donde las fortunas son el fruto del trabajo, de la industria, de los talentos y del genio, pero donde la ley no ha hecho nada para limitarlos, la sociedad debe a aquellos de sus miembros que no tienen ninguna propiedad, y cuyo trabajo es apenas suficiente para cubrir sus necesidades, una subsistencia asegurada, suficiente para alimentarse, vestirse y alojarse adecuadamente; para curarse en sus enfermedades, en su vejez, y para criar a sus hijos. Esta es la recompensa por el sacrificio que han sufrido en sus derechos comunes a los productos de la tierra, y del pacto por el que se han comprometido a respetar las propiedades de sus conciudadanos. ${ }^{10}$

Marat no habla aquí de ese derecho a la asistencia dirigido a las gens de bras del que se hacen eco Pétion, Target y Sieyes. Distingue, en cambio, dos clases de ciudadanos que en los anteriores proyectos estaban mezcladas: los propietarios y los trabajadores. Estos últimos contribuyen a la riqueza de la nación, pero, al no tener acceso a la propiedad, no disfrutan de ella. La sociedad les debe, por tanto, una existencia digna. De lo contrario, el pobre ya no está obligado ni a trabajar ni a respetar la propiedad de los ricos.

Marat considera que la garantía del derecho a la existencia requiere una redistribución de la propiedad. En una sociedad bien ordenada, afirma, los ciudadanos deben disfrutar aproximadamente de las mismas ventajas. En caso contrario, el pacto social no está respetando los derechos naturales de todo individuo. Esto no quiere decir, como el propio Marat se encarga de precisar, que se deba instaurar una igualdad niveladora. Las desigualdades sociales, siempre que estén basadas en las desiguales facultades humanas, son tolerables y hasta justas. Ahora bien: la ley debe evitar que se conviertan en excesivas. Debe evitar, sobre todo, que una clase disfrute de todas las ventajas sociales, mientras el resto vive en un mundo de privaciones, fatigas y sufrimientos, con el agravante de que el bienestar de los primeros no se basa en el mérito, sino en "la intriga, la charlatanería, los favores, las malversaciones, las vejaciones y la rapiña".11 En una sociedad como esta, quienes disfrutan de lo superfluo deben contribuir a la satisfacción de las necesidades de quienes carecen de lo necesario.

El 12 de agosto se encarga a un Comité de 5 miembros el examen de las diferentes propuestas presentadas y la elaboración de una sintesis. El resultado,

10 Jean-Paul Marat, Projet de déclaration des droits de l'homme et du citoyen, suivi d'un Plan de constitution juste, sage et libre, Buisson, Paris, 1789, p. 14.

11 Jean-Paul Marat, Projet de déclaration des droits de l'homme et du citoyen, op. cit., pp. 14-15. 
leído el 17 de agosto por Honoré Gabriel Riquetti, conde de Mirabeau, encuentra una gran oposición. El 18, la Asamblea decide que el Comité tendrá por base los proyectos de La Fayette, Sieyes y el sexto bureau. ${ }^{12}$ El 19 de agosto se adoptan, como base para la futura redacción del texto, la mayoría de disposiciones de este último proyecto. La discusión definitiva sobre la Declaración se lleva a cabo, artículo por artículo, entre el 20 y el 26 de agosto.

El 26 de agosto se aprueba el último artículo, el 17, reconociendo el derecho de propiedad. La discusión continúa al día siguiente, proponiéndose, entre otras, la siguiente disposición:

Todos los miembros de la sociedad, si son indigentes o inválidos, tienen derecho a la asistencia gratuita [secours gratuits] de sus conciudadanos. ${ }^{13}$

Charles-François Bouche pide que el examen de este y otros artículos adicionales se lleve a cabo una vez se haya aprobado la Constitución, y su petición es aceptada por la Asamblea. El artículo 17 cierra, así, el catálogo de derechos, entre los que no figura el derecho a la asistencia.

La Declaración empieza afirmando que todos los hombres "nacen y permanecen libres e iguales en derechos", para después enumerar estos "derechos naturales e imprescriptibles": libertad, propiedad, seguridad y resistencia a la opresión, cuya conservación es la "finalidad de toda asociación política". A continuación se esbozan los principios políticos en los que estará basada la futura Constitución: soberanía nacional, igualdad ante la ley, imperio de la ley, libertad de opinión y de culto, establecimiento de una fuerza pública en aras del bien común, impuestos equitativos, protección de la propiedad. Derechos naturales del hombre, por un lado, y derechos del ciudadano, por el otro, entendidos estos últimos como la trasposición de los primeros al estado social. Este será, a partir de entonces, el lenguaje compartido por los distintos actores implicados, el sustrato común desde el que se librarán las disputas ideológicas de la Revolución. ${ }^{14}$

\subsection{El Comité para la extinción de la mendicidad}

E1 20 de agosto de 1789, Pierre-François Boncerf, antiguo colaborador de Turgot, presenta ante la asamblea del distrito parisino de Saint-Etienne-du-Mont una moción titulada "De la nécessité et des moyens d'occuper avantageusement tous les gros ouvriers". Es publicada como panfleto poco después, a instancias de la Asamblea nacional. Para entender el sentido de la intervención de Boncerf, conviene tener en mente esa distinción que hemos hecho al inicio entre gens de

12 El 1 de julio se habian creado en la Asamblea nacional 30 comisiones (bureaux), de 40 miembros cada una, para organizar el trabajo parlamentario en una cámara muy numerosa, y también para evitar que los particularismos - tanto los geográficos como los derivados de la pertenencia de los representantes a cada uno de los tres órdenes (clero, nobleza y tercer estado) primasen sobre el interés general. Una de estas 30 comisiones, la sexta, presenta un conocido proyecto de Declaración.

13 Antoine de Baecque, Wolfgan Schmale y Michel Vovelle, L'An 1 des droits de l'homme, Presses du CNRS, Mesnil-sur-l'Estrée, 1988, p. 195.

14 Véase: Marcel Gauchet, La Révolution des droits de l’homme, Gallimard, Plessis-Trévise, 2010; Florence Gauthier, Triomphe et mort de la Révolution des droits de l'homme et du citoyen (1789-1795-1802), Syllepse, París, 2014. 
métier y gens de bras. La Revolución, afirma, ha hecho que muchos habitantes de las ciudades (citadins) se hayan quedado sin estado (sans état) y sin ocupaciones (sans occupations). Los acontecimientos recientes, continúa, afectan incluso más a los trabajadores no cualificados (gros ouvriers), que se encuentran cada vez más sin trabajo (sans ouvrage). Su panfleto va dirigido a los segundos, y también a aquellos de entre los primeros a quienes los acontecimientos recientes han relegado a la condición de hommes de peine.

La desocupación, afirma Boncerf, aumenta el número de los "hombres peligrosos". Es necesario ocuparlos cuanto antes en trabajos útiles, para impedir que la indolencia los corrompa y, sobre todo, para evitar que se reúnan, porque juntos son capaces de todo tipo de crimenes. Teniendo esto en cuenta, ¿de qué manera se deben organizar los trabajos públicos?

En las urgentes circunstancias en las que se encuentra París actualmente, no es posible que la ciudad asuma las vastas operaciones requeridas por un plan general; hay que mirar hacia los aledaños, tanto para poner inmediatamente los brazos ociosos a la obra, como para acostumbrar a los individuos a separarse de esta Capital, que les ha ofrecido durante tanto tiempo ocupaciones bien pagadas [occupations chèrement payées], y que les ha retenido por la atracción que ejercen los placeres fáciles y los goces continuos. No les podemos separar de una manera brusca, lo que les privaría de la esperanza de regresar; la moderación es indispensable cuando se trata de tantas personas corruptas. Hay que llevarlos a trabajar no muy lejos de aquí. ${ }^{15}$

En este pasaje se observa bien que, para Boncerf, la asistencia a los pobres es indisociable de su disciplinamiento. Los desocupados merecen ser ayudados, pero al mismo tiempo son responsabilizados de su situación: su miseria material se liga a su miseria moral. La sociedad se ofrece a ayudarlos y a corregirlos, y no dudará en emplear la fuerza contra aquellos que se resistan. Se cuela, además, como no podía ser de otro modo en un discípulo de Turgot, la crítica a las corporaciones de oficios, que han ofrecido hasta ahora un trabajo demasiado bien pagado. Es necesario eliminar todos los obstáculos que se interponen en el camino de la nueva sociedad industriosa. La propuesta de Boncerf se resume muy bien en una frase que él mismo destaca en cursiva: "Los primeros acreedores de la Nación son los brazos que reclaman trabajo, y la tierra que espera a esos brazos". ${ }^{16}$ La nación tiene una deuda con los pobres desocupados, pero no menos sagrada es su deuda con la tierra yerma. La forma de saldar las cuentas con ambos acreedores es reunirlos a las afueras de París, para que puedan contribuir a hacer de Francia un gran taller industrioso y feliz.

El panfleto de Boncerf debe ser leído teniendo en cuenta los problemas a los que pretende dar respuesta. Al inicio de la Revolución, ante la llegada masiva de desempleados a París, el municipio se sirve de los talleres de caridad ${ }^{17}$ para

15 Pierre-François Boncerf, De la nécessité et des moyens d'occuper avantageusement tous les gros ouvriers, Badouin, Paris, 1789, pp. 3-4.

16 Pierre-François Boncerf, De la nécessité et des moyens d'occuper avantageusement tous les gros ouvriers, op. cit., p. 14.

17 Los talleres de caridad (ateliers de charité), creados en 1770, reciben un renovado impulso de 1775 en adelante, a instancias de Turgot. Enfocados fundamentalmente a la construcción de caminos, prestan asistencia a aquellos trabajadores del rural a los que una coyuntura desfavorable ha privado temporalmente de su actividad. Se organizan sobre todo en invierno, cuando hay menos trabajo en el campo. La extensión de los talleres de caridad es solicitada en 
reparar carreteras, demoler la Bastilla o construir una vía hacia Montmartre. E1 taller de caridad de Montmartre atrae rápidamente a miles de trabajadores, una concentración que no tarda en inquietar a las autoridades. Aduciendo problemas de organización, pronto se decide clausurarlo. Los trabajadores son obligados a emprender el camino de vuelta. Poco después se inician otros trabajos públicos en la capital, pero la tendencia es endurecer cada vez más las condiciones de entrada a los talleres urbanos, desplazando la asistencia a las afueras o a las zonas rurales.

En la misma asamblea en la que Boncerf había presentado su moción a finales de agosto, se lee, unos meses más tarde -el 27 de noviembre-, una petición que lleva por título: "Adresse à l'Assemble nationale à sujet d'en obtenir la formation d'un Comité dans son sein pour appliquer d'une manière spéciale à la protection et à la conservation de la classe non propriétaire les grands principes de justice décrétés dans la Déclaration des droits de l'homme et dans la Constitution". Es obra de Jean-François Lambert, ${ }^{18}$ inspector en el Hôpital Général pour le Renfermement des Pauvres de Paris, uno de los asilos más importantes de Francia. El autor recomienda el establecimiento de talleres de caridad para socorrer a los trabajadores desempleados, de forma que estos puedan disfrutar realmente de los principios proclamados en la Declaración de derechos. La libertad, afirma, resulta una palabra vacía para aquellos hombres que no tienen la seguridad de poder subsistir gracias a su trabajo.

No es hasta finales de enero de 1790 que la Asamblea accede a la petición de Lambert. Se crea un Comité, compuesto originalmente por cuatro personas, destinado a ocuparse de la clase más pobre de la población. El 2 de febrero celebra su primera sesión. El 1 de abril cuenta ya con 18 miembros (entre ellos, Boncerf y Lambert). Su nombre es Comité pour l'extinction de la mendicité (Comité para la extinción de la mendicidad) y está presidido por François Alexandre Frédéric de La Rochefoucauld, duque de Liancourt. Permanece activo hasta septiembre de 1791.19

A partir del 26 de febrero, el trabajo del Comité se organiza en secciones. Cada una se ocupa, entre otros asuntos, de los niños abandonados, los pobres enfermos, los trabajos destinados a los pobres válidos, la asistencia a los ancianos e inválidos, las casas de corrección, las prisiones y las deportaciones de mendigos. A pesar de esta división del trabajo por secciones, el hecho de que un mismo comité esté encargado de cuestiones tan diversas resulta chocante desde nuestra visión actual. El Comité de mendicidad organiza tanto el cuidado de los pobres enfermos como los trabajos destinados a los pobres válidos; asiste a los ancianos y a los niños, al tiempo que encierra y deporta a los mendigos y delincuentes. No hay una separación clara entre la sanidad, las obras públicas, la

muchos cahiers de doléances. Véase: William Olejniczak, "Working the Body of the Poor: The 'Ateliers de Charité' in Late Eighteenth-Century France”, Journal of Social History, n' 24, vol. 1, 1990, pp. 87-107; Anne Conchon, "Les travaux publics comme ressource : les ateliers de charité dans les dernières décennies du XVIII" siècle", Mélanges de l'École française de Rome - Italie et Méditerranée modernes et contemporaines, $\mathrm{n}^{\circ}$ 123, vol. 1, 2011, pp. 173-180.

18 No confundir con el poeta Jean-François de Saint-Lambert.

19 El 29 de octubre de 1791 tiene lugar la primera sesión de su sucesor, el Comité des secours publics (Comité de asistencia pública), que desarrolla su actividad durante la Asamblea legislativa y la Convención. 
dependencia y el sistema penitenciario. Todo queda englobado en el difuso concepto de "asistencia" (secours). Se trata de ayudar a los desclasados: si es posible, poniéndolos a trabajar, y si no es posible, cuidándolos, encerrándolos o desterrándolos. Todo ello con el fin último de evitar que se altere el orden público. Esto no quiere decir que para sus promotores la asistencia no sea vista, al mismo tiempo, como una ayuda genuina, como un acto de caridad hacia personas caídas en desgracia.

La siguiente anécdota puede ayudar a entender la ausencia de limites precisos de la que hablamos. El 12 septiembre 1790, la Asamblea nacional acuerda crear, a propuesta de Guillotin, un Comité de salubrité (Comité de salubridad), encargado de organizar el aprendizaje de la medicina, de gestionar los diferentes tipos de establecimientos sanitarios -desde hospitales a residencias de ancianos-y, en general, del mantenimiento de la salud pública. La propuesta de Guillotin, él mismo miembro del Comité de mendicidad, no es bien acogida por Liancourt, que protesta ante la Asamblea. La asistencia a los pobres enfermos, afirma, es una de las atribuciones de su Comité. Si bien es cierto que posteriormente ambos Comités conviven de forma pacífica, el hecho de que un Comité encargado de lo que hoy llamariamos "sanidad" sea visto como una injerencia por el Comité de Liancourt, encargado de la asistencia a los pobres y de las obras públicas, es buena muestra de que, en la época, estas dos esferas se encuentran en buena medida solapadas.

Ahora nos centraremos en algunos informes del Comité, que nos permitirán hacernos una idea de sus actividades y, por extensión, de la forma en que se piensa la asistencia a los pobres durante la Revolución. ${ }^{20}$ No nos ocuparemos de los informes que podemos llamar "técnicos", cuyo objetivo es establecer los principios y las normas de un nuevo sistema público de caridad. Hablaremos únicamente del Plan de Trabajo, así como del Primero y el Cuarto de entre los siete informes que tienen un carácter más teórico.

\subsection{E1 Plan de trabajo del Comité}

Empecemos por el Plan de trabajo, que se publica el 6 de junio de 1790:

Todo hombre tiene derecho a su subsistencia.

Esta verdad fundamental de toda Sociedad, y que reclama imperiosamente un lugar en la Declaración de los Derechos del Hombre, le parece al Comité que debe ser la base de toda Ley, de toda institución politica que se proponga extinguir la mendicidad. Así, puesto que todo hombre tiene derecho a la subsistencia, la Sociedad debe proveer la subsistencia a todos aquellos de entre sus Miembros que carezcan de ella, y esta asistencia caritativa no debe ser vista como un favor; es, sin duda, un acto que deriva necesariamente de un corazón sensible y humano, el deseo de todo hombre

20 De todas formas, existen diferencias relevantes, tanto teóricas como prácticas, entre las diferentes fases de la Revolución. Véase: Louis Parturier, L'Assistance à Paris sous l'Ancien Régime et pendant la Révolution, Champion, Paris, 1897; Ferdinand Dreyfus, L'Assistance sous la Législative et la Convention (1791-1795), Société Nouvelle de Librairie et d'Édition, París, 1905. No confundir a este último con el periodista Ferdinand-Camille Dreyfus, ni con el famoso oficial Alfred Dreyfus. Sobre el Comité de mendicidad, véase: Jean-Baptiste Masméjan, "Le comité de mendicité mandaté par la nation : vers une harmonisation de la politique d'assistance des valides (1790-1791)", Cahiers Jean Moulin, n 2, 2016, pp. 1-22. 
que piensa, pero es también el deber estricto e indispensable de todo hombre que no está él mismo en un estado de pobreza; un deber que no debe envilecerse ni con el nombre ni con la naturaleza de la limosna; en definitiva: es para la Sociedad una deuda inviolable y sagrada. ${ }^{21}$

La radicalidad de este párrafo, que parece anticipar reivindicaciones futuras, es matizada enseguida, en el párrafo siguiente:

Para dar a esta verdad toda su fuerza, hay que reconocer que el trabajo es el medio de subsistencia que debe darse a los pobres capaces de trabajar; que el pobre válido al que el vicio aleja del trabajo solamente tiene derecho a lo estrictamente necesario para la subsistencia, de modo que la sociedad no se convierta, al negársela, en culpable de su muerte; que, finalmente, los pobres inválidos tienen derecho a una ayuda completa; de todo ello se sigue que si bien es un deber exacto e indispensable de todo hombre en sociedad contribuir a la subsistencia de aquellos que no pueden ganarse la vida, toda contribución que la sociedad exija para este fin más allá de lo que es estrictamente necesario se convierte en una violación de la propiedad y, en consecuencia, en una injusticia. ${ }^{22}$

Del derecho a la subsistencia de todo hombre hemos pasado, sin tiempo para digerir el cambio, a una clasificación entre tres tipos de pobres. A los pobres válidos que estén desocupados hay que ponerlos a trabajar. A aquellos que puedan trabajar pero se nieguen a hacerlo -en las condiciones que los empresarios privados o la fuerza pública establezcan, se sobreentiende- nada se les debe: hay que reprimirlos, asegurándose únicamente de que no se mueran de hambre. A los inválidos, puesto que no tiene sentido exigirles el deber de trabajar, hay que proporcionarles una ayuda equivalente al salario que reciben los pobres válidos que trabajan. Estas tres precisiones hechas al derecho a la subsistencia, se afirma finalmente, responden a la salvaguarda de otro derecho fundamental, este sí reconocido expresamente en la Declaración, en su último artículo. La ayuda a los pobres sale de los bolsillos de los ricos, a través del impuesto: llevarla más allá de ciertos límites sería cometer una injusticia contra los propietarios.

Más adelante se insiste en esta división tripartita, que es en realidad una distinción entre dos tipos de pobres: los buenos y los malos, los verdaderos y los falsos.

Primera división: los verdaderos pobres, es decir, aquellos que, sin propiedad ni recursos, quieren ganarse su propia subsistencia a través del trabajo; aquellos a quienes la edad no permite todavía o ya no permite más trabajar; finalmente, aquellos que están condenados a una inacción permanente por la naturaleza de sus minusvalías, o a una inacción temporal por enfermedades pasajeras.

Segunda división: los malos pobres, es decir, aquellos que, conocidos bajo el nombre de mendigos de profesión y vagabundos, rechazan cualquier

21 Camille Bloch y Alexandre Tuetey, Procès-verbaux et rapports du Comité de mendicité de la constituante : 1790-1791, Imprimerie Nationale, París, 1911, p. 310.

22 Camille Bloch y Alexandre Tuetey, Procès-verbaux et rapports du Comité de mendicité de la constituante, op. cit., pp. 310-311. 
trabajo, perturban el orden público, son una epidemia en la sociedad y deben ser tratados con justa severidad.23

El desmoronamiento de la sociedad de los privilegios abre a todos la senda del éxito y la prosperidad. La sociedad debe acudir en ayuda de los que se caigan por el camino, siempre que se comprometan a trabajar o que estén incapacitados para ello. A todos los demás les espera la represión. Estas son, simplificando, las tres fases del plan del Comité para acabar con la mendicidad. Primero, libertad de trabajo; es decir, eliminación de los privilegios de la vieja sociedad, de forma que todos puedan ganarse libremente su sustento. Después, asistencia para aquellos que no puedan proveerse por si mismos su subsistencia, sea porque están incapacitados para trabajar, sea porque carecen temporalmente de ocupación. Por último, medidas represivas hacia aquellos que no se ajustan al plan.

El punto más problemático de este esquema es el tratamiento que merecen los pobres válidos sin trabajo, que pueden ser tanto gens de bras desocupadas como gens de métier a quienes las circunstancias han degradado a la condición de los primeros. Es aquí donde pondremos el foco, por ser el lugar donde mejor se aprecia el verdadero alcance de la legislación social propuesta por el Comité. Sin duda, los pobres desocupados tienen, como todo hombre, derecho a la subsistencia. Ahora bien, ¿quién debe garantizarles dicha subsistencia? ¿Las instituciones públicas, de forma inmediata? $¿ O$ más bien se trata de un futurible, de un derecho condicionado al desarrollo de la sociedad en una determinada dirección? Como veremos enseguida, estamos más bien ante lo segundo, aunque eso no excluya algunas actuaciones dirigidas en el primer sentido. En estos casos, en los que las instituciones se ocupan directamente de la suerte de los desgraciados, ¿qué nivel de ayuda les corresponde? ¿Tienen derecho al mismo nivel de vida que los ricos? Es evidente que no. ¿Y al de los pobres que se ganan honradamente la vida con su trabajo? Enseguida veremos que tampoco.

\subsection{E1 Primer Informe}

El Primer Informe, publicado el 15 de junio de 1790, empieza insistiendo en las novedades que supone la existencia del Comité de mendicidad, la nueva perspectiva sobre la pobreza que este pretende inaugurar:

Este es el gran principio que durante mucho tiempo ha sido desconocido en nuestras instituciones sociales:

'La miseria de los pueblos es culpa de los gobiernos'. ${ }^{24}$

El Comité se sirve del conocido principio roussoniano que culpa a los gobiernos de los males de los individuos, pero lo hace dándole un nuevo sentido. La nueva comunidad politica debe hacerse cargo de los pobres de una manera distinta a como se ha hecho hasta ahora. Ya no se trata de aliviar la miseria simplemente por razones de caridad o de orden público, sino de asegurarse de que no se desperdicia el trabajo productivo de la nación. La miseria es culpa de los gobiernos porque estos, si siguen los principios de la ciencia nueva de la

23 Camille Bloch y Alexandre Tuetey, Procès-verbaux et rapports du Comité de mendicité de la constituante, op. cit., p. 317.

24 Camille Bloch y Alexandre Tuetey, Procès-verbaux et rapports du Comité de mendicité de la constituante, op. cit., p. 327. 
economía política, tienen en su mano asegurar la riqueza de las naciones. Si la nación está fundada en el trabajo, como dicen los economistas, entonces hay que situar las normas que regulan su administración y fomento entre los principios fundamentales de la comunidad política, es decir, en la Constitución.

Hasta ahora, ningún Estado ha tenido en cuenta a los pobres en la Constitución. Muchos se han ocupado de proporcionarles ayuda, muchos han investigado sobre los principios que debían guiar esa administración, algunos se han acercado a ellos; pero en ningún país las leyes que los establecen forman parte de la Constitución. Siempre se pensó en hacer actos de caridad hacia los pobres, pero nunca en hacer valer los derechos del hombre pobre sobre la sociedad, y los de la sociedad sobre él.25

Como se recordará, en el Plan de trabajo se decía que todo hombre tiene un derecho natural a la subsistencia. Ya hemos dicho que alli no se terminaba de concretar la forma en que se debia trasladar este derecho al estado social, especialmente en el caso de los pobres válidos sin trabajo. Ahora el Comité precisa que se trata de una cuestión de derechos, y no de simple caridad. Aunque no haya encontrado un lugar en la Declaración provisional de agosto, la asistencia pública debe figurar en la futura Constitución. Esto es así porque, en el estado social, nadie puede encontrarse en una situación peor de la que tendría en el estado de naturaleza: en caso de que alguien no tenga la subsistencia asegurada, está legitimado a impugnar el pacto. Ahora bien: a diferencia de lo que sucede con los derechos proclamados en el 89, el derecho a la subsistencia del que habla el Comité no se ajusta perfectamente a la lógica de los derechos naturales. Si aquellos eran derechos imprescriptibles de todo individuo, finalidad de toda asociación política, este es un derecho situado al mismo nivel que los "derechos" de la sociedad sobre el individuo:

Si quien existe tiene el derecho de decirle a la sociedad: hazme vivir, la sociedad tiene igualmente el derecho de responderle: entrégame tu trabajo. ${ }^{26}$

Dicho con otras palabras: en el caso de la asistencia pública, y a diferencia de lo que sucede con otros asuntos, los derechos del individuo resultan inseparables de sus deberes. Por un lado, la sociedad debe al pobre su subsistencia, y el pobre tiene derecho a exigirle una subsistencia digna. Por el otro, el pobre debe a la sociedad su trabajo, y la sociedad tiene derecho a exigirle que trabaje.

Además de obligatorio, es un trabajo mal remunerado:

El hombre rescatado por la Nación y que está a su cargo debe estar, sin embargo, en peores condiciones que si no necesitara ayuda y pudiera existir por sus propios medios. 27

El Comité dice, a este respecto, que no se debe confundir la justicia con la caridad. Dejarse llevar por los impulsos del corazón no soluciona el problema de la indigencia, sino que lo agrava, al conducir a los pobres por los caminos de la

25 Camille Bloch y Alexandre Tuetey, Procès-verbaux et rapports du Comité de mendicité de la constituante, op. cit., p. 328.

${ }^{26}$ Camille Bloch y Alexandre Tuetey, Procès-verbaux et rapports du Comité de mendicité de la constituante, op. cit., p. 327.

27 Camille Bloch y Alexandre Tuetey, Procès-verbaux et rapports du Comité de mendicité de la constituante, op. cit., p. 330. 
pereza y la ociosidad. Si se quiere extirpar el mal de la mendicidad de raíz, hay que fomentar la utilidad y laboriosidad de los pobres, ayudándolos únicamente en la medida en que ello les permita volver a entrar en los mercados de trabajo. Se excluye, de forma explícita, la posibilidad de que el Estado ofrezca un puesto de trabajo a todo aquel que llame a su puerta. Hay que incitar al pobre a que se busque la vida por sí mismo:

Si el trabajo se le ofrece cada vez que se presenta, en el lugar más cercano y de la naturaleza más fácil, la sociedad le dispensa de la necesidad de intentar encontrarlo por sí mismo, y le prohíbe, por así decirlo, toda industria; dándole trabajo de esta manera, la sociedad cae en el inconveniente que quería evitar al negarle ayuda gratuita, favorece la pereza, la dejadez, cuando debería fomentar la actividad y la previsión. ${ }^{28}$

Ofrecer un trabajo de forma abundante y con buenas condiciones es casi tan mala solución como ofrecer ayudas públicas sin pedir una contrapartida. Ambas estrategias favorecen la pereza. Al mismo tiempo, el trabajo ofrecido debe tener alguna utilidad para la sociedad: su finalidad no debe ser solo disciplinaria, sino ante todo productiva.

Si la sociedad no proporciona más que trabajos inútiles, comete el error de autorizar la holgazaneria, porque el hombre trabaja mal en una tarea de la que sabe su inutilidad, así como de gastar sin provecho los fondos comunes. ${ }^{29}$

Teniendo esto en cuenta, surge la pregunta: ¿qué tipo de trabajos públicos están en grado de cumplir con estos principios establecidos por el Comité? Deberán ser trabajos útiles y capaces de impulsar la laboriosidad, pero al mismo tiempo escasos y sacrificados. Uno tiene la sospecha (pronto veremos que confirmada) de que, a no ser que el país se encuentre en una situación de crisis, el Comité no es favorable a que el las instituciones públicas se ocupen activamente de la asistencia a los desocupados.

\subsection{E1 Cuarto Informe}

En efecto, el Cuarto Informe, publicado el 31 de agosto de 1790, refuta extensamente la tesis de que un gobierno sabio debe, en los tiempos ordinarios, proporcionar trabajo a todos aquellos que no puedan procurárselo por sí mismos. Este informe puede ser leído como la justificación teórica del decreto de la Asamblea nacional promulgado ese mismo dia. El artículo 1 suprime los talleres de caridad actualmente existentes en París, al tiempo que insta a la creación inmediata, tanto en París como en los diferentes departamentos, de otros nuevos. El artículo 2 divide estos nuevos talleres en dos clases: en los primeros, se pagará por pieza o tarea realizada; en los segundos, pensados para personas más débiles o poco acostumbradas a los trabajos en el sector de la construcción (travaux de terrasse), los trabajadores recibirán un jornal. En el artículo 3 se especifica que ambos tipos de salario deberán mantenerse por debajo del precio de mercado. En el artículo 4 se anuncian sanciones para aquellos que vayan contra las normas que serán establecidas. En el 5 se endurecen las condiciones de entrada para los

28 Camille Bloch y Alexandre Tuetey, Procès-verbaux et rapports du Comité de mendicité de la constituante, op. cit., p. 331.

29 Camille Bloch y Alexandre Tuetey, Procès-verbaux et rapports du Comité de mendicité de la constituante, op. cit., p. 331. 
talleres de París (Duvergier, 1834, 1: 350-351). En definitiva: los talleres de caridad, que desde entonces pasan a llamarse talleres de asistencia (ateliers de secours), se vuelven más jerárquicos y coercitivos. Es la antesala de su cierre, que se produce el verano siguiente. Desde julio de 1791 , solo siguen funcionando los talleres de hilado, destinados a las mujeres y los niños. Habrá que esperar a 1793 para que vuelvan a entrar en funcionamiento.

Como deciamos, el Cuarto Informe rechaza la idea que el gobierno deba ocuparse de crear directamente puestos de trabajo. Tiene que limitarse a alentar el trabajo, a multiplicar los medios que hacen posible su desarrollo.

Para que el gobierno pueda dar trabajo individualmente a todos los que carecen de él, tendría que poder conocer con precisión quiénes son los que realmente no pueden encontrarlo, y tendría además que disponer de tareas útiles para dar en función de las necesidades de aquellos brazos que quisieran solicitarlas, y en función del momento en que las solicitaran; y ciertamente estas dos condiciones presentan terribles dificultades. ${ }^{30}$

Una cosa es poner a trabajar a las afueras de París a las gens de bras, y otra distinta encontrar un trabajo a las gens de métier que hayan caído en desgracia, teniendo en cuenta las habilidades particulares de cada oficio. Lo segundo, opina el Comité, no resulta viable. De la misma manera, es muy problemático saber cuándo alguien no tiene trabajo porque no quiere o porque realmente no ha podido encontrarlo. El Estado debería ser capaz de distinguir estos dos tipos de pobres, si no quiere favorecer el gorroneo y la incuria.

El Comité propone continuar con el establecimiento de talleres de caridad, pero como un recurso secundario. Su mantenimiento, se dice explícitamente, no tiene que ver con las grandes cuestiones que le ocupan. Estos talleres no están en grado de solucionar el problema de la indigencia. Pueden, a lo sumo, evitar algunas de sus consecuencias más perniciosas. Pero el verdadero objetivo del Comité es otro, a la vez más ambicioso y más indeterminado: no se trata tanto de asegurar un derecho a través de la acción gubernamental, como de favorecer el desarrollo de una nueva sociedad, más dinámica y ahorradora.

El gobierno no debe ser previsor para cada particular; debe inculcar en cada individuo esta necesidad individual; debe dejar que la influencia de las diversas relaciones sociales actúe, y no favorecer la extinción de la caridad particular por un contexto que impide su ejercicio.

Pero si el gobierno no debe ser previsor para cada individuo, tiene el deber de serlo para todos. Es a través de su legislación general que debe garantizar, a todos aquellos para quienes el trabajo es necesario para existir, medios seguros para poder procurárselo. ${ }^{31}$

Estos "medios seguros" no consisten en una ayuda directa. La libertad de trabajo, y la liberalización más general de la economía, son para el Comité la única forma de extinguir realmente la mendicidad. Más allá de alguna actuación concreta destinada a socorrer a los miserables, los deberes fundamentales de la sociedad - a la hora de asegurar el derecho a la subsistencia de los ciudadanos-

30 Camille Bloch y Alexandre Tuetey, Procès-verbaux et rapports du Comité de mendicité de la constituante, op. cit., p. 427.

31 Camille Bloch y Alexandre Tuetey, Procès-verbaux et rapports du Comité de mendicité de la constituante, op. cit., p. 431. 
son deberes de abstención: las autoridades deben dejar hacer a los agentes privados. La supresión de las estructuras arcaicas en la organización del trabajo, herencia caduca de un régimen de privilegios, se concibe como el mejor medio de erradicar completamente la indigencia.

Esta solución puede resultar paradójica, o incluso contradictoria con los principios enunciados por el propio Comité. Si realmente "la miseria de los pueblos es culpa de los gobiernos", la consecuencia que se sigue necesariamente de esta afirmación, podría pensarse, es que los gobiernos deben ocuparse directamente de la cuestión. Las cosas, con todo, no son tan sencillas. En el plano teórico, la solución del Comité al problema de los pobres sin ocupación es clara: hay que asegurar su subsistencia poniéndolos a trabajar. El problema está en que este deber de la sociedad puede concretarse en medidas de signo diverso, incluso contrario. No conduce, al menos no de forma inequívoca, al reparto de tierras, ni tampoco a la contratación de trabajadores para la realización de obras públicas. Es un deber que puede considerarse colmado con la simple apertura de los mercados de trabajo. En un momento en el que se está saliendo de la vieja sociedad de los privilegios, la liberación del trabajo puede aparecer aun como la mejor forma de dar solución al problema de la desocupación. ${ }^{32}$

\subsection{La Constitución de 1791}

El 3 de septiembre de 1791, la Asamblea nacional promulga una nueva Constitución para Francia. Establece una monarquía constitucional con sufragio censitario y está encabezada por la Declaración de derechos de 1789. Recordemos que el derecho a la asistencia no había sido finalmente incluido en la misma. Este vacío es subsanado en el Título I, que recoge las "Disposiciones fundamentales garantizadas por la Constitución". En la séptima de estas disposiciones se puede leer:

Se creará y organizará un establecimiento general de asistencia pública [Secours publics], para educar a los niños abandonados, socorrer a los pobres inválidos [infirmes], y suministrar trabajo a los pobres válidos que no hayan podido procurárselo. 33

La ley fundamental insta a la creación de un sistema público de asistencia. Se podría pensar que, en la medida en que una de las formas de proporcionar asistencia es "suministrar trabajo a los pobres válidos", las instituciones se comprometen a ocuparse activamente del problema de la desocupación. En mi opinión, a la luz de todo lo que llevamos dicho hasta ahora, ese no es el sentido que la mayoría de los constituyentes de 1791 pretenden darle a esta disposición fundamental. La provisión pública de trabajo, se dice explícitamente en el artículo, está dirigida únicamente a aquellos pobres válidos que no hayan podido conseguirlo en los mercados privados. Como muestran los trabajos del Comité de mendicidad, las nuevas instituciones no están dispuestas a abrir mucho la mano

32 En marzo de 1791, el decreto de Allarde suprimirá las corporaciones de oficios. En junio del mismo año, la ley Le Chapelier prohibirá las coaliciones de trabajadores y de empresarios, en nombre de la libertad de trabajo y del libre juego de las voluntades individuales en los mercados.

33 Constitution du 3 septembre 1791: https://www.conseil-constitutionnel.fr/lesconstitutions-dans-1-histoire/constitution-de-1791. En la página web del Conseil Constitutionnel se pueden consultar las diferentes Constituciones de la historia de Francia. 
a este respecto: solo intervendrán en caso de que los pobres se encuentren ante la imposibilidad absoluta de encontrar trabajo, y los asistirán con un trabajo sacrificado y mal remunerado.

En definitiva: en la Constitución de 1791, la asistencia pública no es un derecho de todos los ciudadanos, sino una ayuda centrada en aquellos caídos en desgracia: niños abandonados, inválidos y desgraciados. El objetivo no es eliminar la miseria, sino evitar que sea excesiva, a través de un sistema público de caridad. Como ya había adelantado el Comité de mendicidad, la suerte de los pobres merece, por primera vez en la historia, un lugar en la Constitución. No se reconoce todavía a esos pobres, en cualquier caso, como ciudadanos de pleno derecho.

\section{EN TORNO A LA CONSTITUCIÓN DE 1793}

\subsection{Nuevos proyectos de Declaración}

E1 29 de septiembre de 1792, un decreto de la Convención crea una comisión encargada de elaborar una nueva Constitución para Francia. El 11 de octubre se decide que estará compuesta por nueve miembros: Brissot (sustituido después por Barbaroux), Vergniaud, Gensonné, Pétion, Condorcet, Sieyes, Barère, Danton (que finalmente causa baja) y Thomas Paine. La figura principal del grupo es Condorcet, el último filósofo ilustrado. La influencia del abate Sieyes es reducida, y otro tanto sucede con Paine, que acaba de llegar a Francia y no conoce todavía el idioma. Ideológicamente, la comisión es de mayoría girondina (Barbaroux, Vergniaud, Gensonné y Pétion, además de Condorcet), con un solo miembro de la Llanura (Barère) y, tras la renuncia de Danton, ninguno de la Montaña.

Los trabajos no se inician hasta después de la ejecución del rey, el 21 de enero de 1793. Los miembros de la comisión eligen como base de la discusión una propuesta de Condorcet, que contiene un "Projet de déclaration des droits naturels, civils et politiques des hommes". Este proyecto es presentado el 15 y 16 de febrero de 1793 ante la Convención. Nos interesa fijarnos en la forma en que se reconoce el derecho de propiedad y, sobre todo, el deber de asistencia pública. El artículo 18 afirma:

El derecho de propiedad consiste en que todo hombre es libre [est le maître] de disponer a su antojo [à son gré] de sus bienes, de sus capitales, de sus rentas y de su industria. ${ }^{34}$

E1 24 establece:

La asistencia pública es una deuda sagrada de la sociedad; corresponde a la ley determinar su alcance y aplicación. ${ }^{35}$

La propuesta no convence, así que la Convención decide, el 17 de febrero, que se sigan presentando proyectos. La discusión sobre la nueva Constitución queda aplazada por el momento.

\footnotetext{
34 Lucien Jaume (ed.), Les Déclarations des droits de l'homme, op. cit., p. 242.

35 Lucien Jaume (ed.), Les Déclarations des droits de l’homme, op. cit., p. 242.
} 
Mientras tanto, los parlamentarios siguen ocupándose de la ayuda a los pobres. El 19 de marzo de 1793 se aprueba un decreto que establece la nueva organización de la asistencia pública. Los principios en los que se basa el articulado son los siguientes:

1. Que todo hombre tiene derecho a su subsistencia a través del trabajo, si es válido, y a través de asistencia gratuita [secours gratuits] si no está en condiciones de trabajar. nacional. 36

2. Que la tarea de proporcionar subsistencia al pobre es una deuda El artículo 8 establece:

Los fondos se asistencia que la República destinará a la indigencia serán divididos de la siguiente manera:

Asistencia a través del trabajo para los pobres válidos, en los tiempos muertos o las épocas de crisis [calamité].

Asistencia a domicilio para los pobres inválidos, sus hijos, los ancianos y los enfermos. ${ }^{37}$

El artículo 14 afirma:

La mendicidad será reprimida. En cada departamento se establecerán casas de represión y de trabajo, donde serán conducidos los mendigos, en los casos y durante el tiempo que se determine. 38

Como puede observarse, no hay grandes novedades con respecto a las tesis del Comité de mendicidad, que ya hemos comentado por extenso.

El 4 de abril se retoma la discusión sobre el texto constitucional. Se nombra un Comité de análisis, encargado de examinar las diferentes propuestas recibidas. Está formado por Debry, Mercier, Valazé, Lanjuinais, Barère y Romme (el único montagnard). El 17 de abril, este último presenta un proyecto alternativo al de Condorcet. En la introducción, el diseñador del calendario republicano distingue entre derechos naturales y derechos sociales (del hombre en sociedad). Empieza ocupándose de los primeros. Todo individuo, afirma, tiene derecho a emplear sus facultades para satisfacer las necesidades que van ligadas a su naturaleza humana. En consecuencia, los frutos de su trabajo, y su propia facultad de trabajar, son sus derechos naturales, son "propiedades" suyas.

Si los derechos naturales tienen que ver con la búsqueda individual de bienestar, los derechos sociales son los que el individuo exige a los demás, estando dispuesto, en consecuencia, a que le sean exigidos a él por parte de otros. Si bien sería antinatural intentar establecer una igualdad social absoluta, sin tener en cuenta las desiguales facultades humanas, argumenta Romme, es preciso, en cambio, reducir la desigualdad social excesiva, y especialmente aquella que no se funda en el mérito. Todos deben tener un mínimo asegurado.

36 Jean-Baptiste Duvergier, Collection complète des Lois, Décrets, Ordonnances, Réglemens et Avis du Conseil-d'État, tomo 5, A. Guyot et Scribe, París, 1834, p. 204. Las normas juridicas promulgadas durante la Revolución Francesa se pueden consultar, también, en la colección de Baudouin: https://collection-baudouin.univ-paris 1.fr.

37 Jean-Baptiste Duvergier, Collection complète des Lois, op. cit., p. 204.

38 Jean-Baptiste Duvergier, Collection complète des Lois, op. cit., pp. 204-205. 
Solamente cuando todos tienen sus necesidades básicas cubiertas, son legítimas las diferencias en el acceso a la propiedad entre ricos y pobres.

El mismo dia, el diputado de la Llanura Jean-Baptiste Harmand afirma:

Los hombres honestos admitirán conmigo que, después de haber obtenido la igualdad política de derecho, el deseo más actual, el más activo, es el de la igualdad de hecho. Digo más, digo que sin el deseo o la esperanza de esta igualdad de hecho, la igualdad de derecho no sería más que una ilusión cruel que, en lugar de los goces que prometió, haría padecer el suplicio de Tántalo a la porción más numerosa y más útil de los ciudadanos. ${ }^{39}$

Ese gran Tántalo que son las clases laboriosas sufre la sed y el hambre en medio de una abundancia que ha creado con sus propias manos. En el estado de naturaleza, los hombres son desiguales de hecho, pero iguales en derechos, afirma Harmand. En el estado social, una cierta igualdad de hecho debe ser asegurada, a fin de que los más fuertes no opriman a los débiles:

¿Cómo pueden las instituciones sociales proporcionar al hombre la igualdad de hecho que la naturaleza le ha negado, sin violar la propiedad territorial e industrial? ¿Cómo lograrlo sin la ley agraria y sin el reparto de las fortunas? El secreto es muy simple; consiste en prevenir los abusos de la propiedad y de la industria, en impedir que los terratenientes trafiquen con la subsistencia del pobre. 40

Igual que Romme, Harmand no propone establecer la "igualdad de goces", sino limitar las concentraciones excesivas de riqueza y evitar las prácticas especulativas con los productos de primera necesidad. El derecho natural que todos tienen a los frutos de su industria, combinado con la diferencia de facultades de cada uno, genera grandes desigualdades. Precisamente para asegurar que todos puedan seguir disfrutando de este derecho natural en el estado social, es necesario limitar el derecho de propiedad, evitando que toda la riqueza social se concentre en unas pocas manos. Tanto en Romme como en Harmand, en definitiva, se combina una visión individualista del estado de naturaleza -en el que los individuos, a fin de satisfacer sus necesidades, adquieren propiedades a través de su trabajo-, con los límites impuestos por el estado social, que tienen que ver con asegurar a todos una existencia digna.

Estos intentos de matizar la forma en que se reconocía el derecho de propiedad en el proyecto de Condorcet provocan la reacción de los girondinos. Algunos responden dudando sobre la necesidad de establecer una Declaración de derechos naturales antes de que se proclame la Constitución. Se sitúan, en definitiva, en la misma posición que en agosto de 1789 habían adoptado monárquicos como Malouët. El Derecho natural empieza a ser percibido como un lenguaje peligroso por quienes desean detener la Revolución, en la medida en que

39 Jérôme Mavidal y Émile Laurent, Archives parlementaires : de 1787 à 1860. Recueil complet des débats législatifs \& politiques des chambres françaises. Première série (1787-1799), tomo 62, Paul Dupont, París, 1902, p. 271. Otra buena compilación de los discursos parlamentarios durante la Revolución es la de Philippe-Joseph-Benjamin Buchez y Pierre-Célestin RouxLavergne, Histoire parlementaire de la Révolution française ou Journal des assemblées nationales depuis 1789 jusqu'en 1815, Paulin, París. Alternativamente, véase la Gazette nationale ou Le Moniteur Universel, disponible en Gallica:

https://gallica.bnf.fr/ark:/12148/cb34452336z/date.item. O bien la página web del French Revolution Digital Archive: https://frda.stanford.edu.

40 Jérôme Mavidal y Émile Laurent, Archives parlementaires, op. cit., p. 272. 
sirve para mostrar la falta de correspondencia entre los principios proclamados en el 89, idealmente compartidos por todos, y unas instituciones que no parecen dispuestas a transformar la sociedad para asegurar su realización efectiva.

Después de la polémica, la Convención decide mantener el texto de Condorcet como base del debate en el pleno. El que se suele conocer como "proyecto girondino" mantiene, a grandes rasgos, el articulado del filósofo ilustrado, aunque significativamente deja de hablar de derechos naturales y se limita a los derechos del hombre en sociedad.

El 22 de abril, el montagnard Charles-François Oudot ${ }^{41}$ propone reconocer el deber de asistencia pública que aparece en el proyecto de Condorcet y en el proyecto girondino (artículos 24 y 23, respectivamente) como un derecho fundamental de todo individuo. A continuación, propone garantizar este derecho a través de la riqueza superflua de los propietarios.

Ha llegado el momento de que el hombre que posee más allá de lo necesario aprenda que es para él un deber contribuir con aquello que le resulta superfluo a la subsistencia de aquellos de entre sus conciudadanos a los que su trabajo no les llega para vivir. ${ }^{42}$

Propone el siguiente artículo:

Todo hombre al que su trabajo le es insuficiente para subvenir su subsistencia tiene el derecho de reclamar la asistencia de la sociedad, de forma que esta le ofrezca emplear sus facultades a su servicio.

La sociedad tiene el derecho de prohibir la mendicidad y de obligar al hombre ocioso a trabajar, ofreciéndole asistencia. ${ }^{43}$

Robespierre va un paso más allá:

No me gustaría que en una declaración, como lo es la Declaración de los derechos del hombre, se emplee una expresión que presupone que vuestra constitución no será capaz de alcanzar el bienestar social. Es sin duda bello anunciar que habrá asistencia pública, pero es cruel y desesperanzador, en lo que se refiere a la imperfección de las instituciones sociales, el suponer, en una constitución, que habrá personas en una situación miserable [des malheureux]. Propongo a la Asamblea la siguiente redacción:

'La subsistencia se debe a todos; la sociedad debe asegurarla a todos sus miembros'. ${ }^{4}$

El girondino Pierre Victurnien Vergniaud le responde:

Suscribiría con mucho gusto la moción de Robespierre, si no la encontrara infinitamente demasiado general. Me parece que los miembros, que entran en sociedad, no deben entrar para que la sociedad los mantenga, sino para procurarse por si mismos medios de subsistencia. Preferiria que se redactara así el artículo 23:

'Todo hombre tiene derecho a subsistir, sea a través de su trabajo, sea a través de la asistencia pública'. ${ }^{45}$

\footnotetext{
${ }^{41}$ No confundir con el cura François Oudot.

42 Jérôme Mavidal y Émile Laurent, Archives parlementaires, op. cit., tomo 63, 1903, p. 110.

43 Jérôme Mavidal y Émile Laurent, Archives parlementaires, op. cit., p. 110.

44 Jérôme Mavidal y Émile Laurent, Archives parlementaires, op. cit., p. 110.
} 
El girondino Jean-Baptiste Boyer-Fonfrède, perteneciente a una gran familia de comerciantes de ultramar, es incluso más explícito. Aunque su argumentación va en la linea de lo expresado por Vergniaud, es partidario de suprimir el artículo, se entiende que para evitar que pueda ser interpretado de forma extensiva:

Sería muy peligroso decretar que la sociedad debe los medios de existencia a los individuos. [...] la sociedad solamente debe asistencia a los inválidos, a quienes han sido desgraciados por la naturaleza y ya no pueden vivir de su trabajo. [...] convertiríais a la sociedad en miserable y pobre, acabariais con la industria y el trabajo, si asegurarais la subsistencia a todos aquellos que no tienen nada, pero que pueden trabajar. ${ }^{46}$

Finalmente se aprueba el artículo 23 , tal y como había sido redactado en el proyecto de Condorcet: la asistencia pública es una deuda sagrada de la sociedad. Romme intenta añadir un párrafo adicional, en el que se afirme: "Todo hombre tiene el derecho de exigir a la sociedad, para sus necesidades, trabajo o asistencia”, pero su propuesta no tiene éxito.

Sobre esto último conviene hacer una precisión. La discusión sobre la asistencia pública que acabamos de resumir no gira en torno a si se debe reconocerla como un derecho del individuo o como un deber de la sociedad. Esa diferencia, que será motivo de grandes disputas en otros períodos históricos, no tiene una gran importancia para los parlamentarios de 1793. Lo que está en juego es si se debe reconocer únicamente un derecho a la asistencia para los inválidos o si es necesario, además, procurar trabajo a los pobres válidos que se encuentren desempleados. El artículo de Condorcet, en su indefinición, es más bien susceptible de ser interpretado en el primer sentido. En esa dirección apuntan, justamente, las intervenciones de Vergniaud y Boyer-Fonfrède. Esa era también la línea que había marcado, a pesar de toda su retórica aparentemente garantista, el Comité de mendicidad. Oudot y Romme, en cambio, proponen que las instituciones se encarguen activamente de proporcionar trabajo a los desempleados. Es cierto que ambos utilizan el lenguaje de los derechos en lugar de hablar de deberes, pero la discusión no gira, al menos no de forma prioritaria, en torno a la forma: lo que está en juego es la implicación o no de las instituciones públicas en la asistencia a los pobres válidos.

\subsection{E1 proyecto de Robespierre}

El 21 de abril -el día anterior a que se discuta el derecho a la asistencia en la Convención-, Robespierre presenta su proyecto de Declaración de los derechos del hombre y del ciudadano en el club de los jacobinos, donde es aprobado por unanimidad. El 24 lo presenta ante la Convención, con menor éxito.

En el preámbulo, destinado a encabezar la Declaración, se explicita la relación que debe existir entre los derechos naturales de todo hombre y el futuro diseño y funcionamiento de las instituciones sociales. Los primeros son el espejo en el que las segundas deben mirarse:

\footnotetext{
45 Jérôme Mavidal y Émile Laurent, Archives parlementaires, op. cit., p. 110.

46 Jérôme Mavidal y Émile Laurent, Archives parlementaires, op. cit., pp. 110-111.
} 
Los Representantes del Pueblo Francés reunidos en Convención nacional, reconociendo que las leyes humanas que no dimanan de las leyes eternas de la justicia y de la razón no son más que atentados de la ignorancia o del despotismo contra la humanidad; convencidos de que el olvido o el desprecio de los derechos naturales del hombre son las únicas causas de los crimenes y de las desgracias del mundo, han decidido exponer [en una Declaración solemne estos derechos sagrados e inalienables], ${ }^{47}$ a fin de que todos los ciudadanos, pudiendo comparar en todo momento los actos del gobierno con el objetivo de toda institución social, no se dejen jamás oprimir ni envilecer por la tiranía; a fin de que el pueblo tenga siempre ante los ojos las bases de su libertad y de su bienestar [bonheur]; el magistrado, la regla de sus deberes; y el legislador, el objeto de su misión. 48

Los cuatro primeros artículos se ocupan de los derechos naturales del hombre. Recordemos que en el proyecto girondino que se está discutiendo ha desaparecido toda mención a los mismos.

I. El objetivo de toda asociación política es el mantenimiento de los derechos naturales e imprescriptibles del hombre, así como el desarrollo de todas sus facultades.

II. Los principales derechos del hombre son el de dotarse de los medios para la conservación de su existencia, y la libertad.

III. Estos derechos pertenecen por igual a todos los hombres, sea cual sea la diferencia de sus fuerzas físicas y morales.

La igualdad de derechos está establecida por la naturaleza: la sociedad, lejos de atentar contra ella, debe garantizarla contra los abusos de poder que la convierten en ilusoria.

IV. La libertad es el poder que pertenece al hombre de ejercer, a su antojo, todas sus facultades. Tiene la justicia como regla, los derechos de los demás como límite, la naturaleza como principio y la ley como salvaguardia. ${ }^{49}$

Los derechos naturales, fin de toda sociedad politica, son solamente dos: la existencia social y la libertad. Esto supone un añadido y varias eliminaciones con respecto a la Declaración de 1789. Por un lado, Robespierre añade el derecho a la existencia. Como veremos, este tiene un alcance mayor que el derecho a la subsistencia defendido por el Comité de mendicidad. Por otro lado, desaparecen la propiedad, la seguridad y la resistencia a la opresión. Tampoco figura la "garantía social", ni la igualdad, que si constaban en el proyecto de Condorcet.

No nos interesa detenernos demasiado en las razones de esta simplificación. Conviene aclarar, en cualquier caso, que la limitación en el número de los derechos naturales no tiene como objetivo disminuir la protección debida a los individuos. La cosa tiene más que ver con la aplicación de la navaja de Ockham.

47 El añadido entre corchetes es mío, en base a: Maximilien Robespierre, Déclaration des droits de l'homme et du citoyen présentée à la Convention nationale en 1793, Rey, Delavigne et Compagnie, París, 1850 , p. 1. Me parece que es necesario para una correcta comprensión del pasaje.

48 Maximilien Robespierre, OEuvres de Maximilien Robespierre. Tome IX : Discours (4ème Partie. Septembre 1792 - Juillet 1793), editado por la VI Section de l'École des Hautes Etudes y la Société des Études Robespierristes, tomo a cargo de Marc Bouloiseau, Georges Lefebvre, Jean Dautry y Albert Soboul, Presses Universitaires de France, París, 1958, pp. 463-464.

49 Maximilien Robespierre, OEuvres de Maximilien Robespierre, op. cit., pp. 464-465. 
La resistencia a la opresión, si se piensa bien, no es un derecho natural en sí mismo, sino el derecho que todo ciudadano tiene de volver al estado constituyente cuando la sociedad no le asegura sus derechos naturales. Otro tanto sucede con la garantía social: más que un derecho natural, es el conjunto de principios políticos que permiten garantizar los derechos naturales en la sociedad politica. ${ }^{50}$ La propiedad, en la medida en que es una palabra que generalmente sirve para justificar la acumulación ilimitada de bienes, a costa del bienestar de la mayoría, no puede ser un derecho natural de todo hombre. Así entendido, es el derecho de una minoria: es un privilegio, no un verdadero derecho. El derecho natural a la propiedad, el que todo hombre tiene sobre sus medios de vida, está incluido en lo que Robespierre llama derecho a la existencia. Con la seguridad sucede algo parecido. Su no inclusión como derecho natural seguramente se debe a que la seguridad pública se ha invocado, durante el curso de la Revolución, para oprimir militarmente al pueblo. Frente a esta seguridad contra el pueblo, el verdadero derecho a la seguridad consiste en que todos tengan asegurados sus derechos naturales; es decir, consiste en que todos tengan cubierta su subsistencia y puedan vivir sin sufrir arbitrariedades o, lo que es lo mismo, en libertad. La igualdad, en fin, tampoco es un derecho natural, sino el reparto igualitario y universal de los derechos naturales. La igualdad de derechos no es un derecho, sino un hecho: "está establecida por la naturaleza". Todos son igualmente libres y todos poseen, aunque de forma diversa, una serie de facultades que les permiten procurarse su subsistencia.

Fijémonos ahora en el derecho a la asistencia, que Robespierre vincula explicitamente a la progresividad en el impuesto:

X. La sociedad está obligada a proveer la subsistencia a todos sus miembros, sea procurándoles trabajo, sea asegurando los medios de existencia a aquellos que se encuentran incapacitados para trabajar.

XI. La asistencia indispensable a quien carece de lo necesario es una deuda de quien posee lo superfluo: corresponde a la ley determinar la manera en que esta deuda debe ser saldada.

XII. Los ciudadanos cuyas rentas no excedan lo que es necesario para su subsistencia están dispensados de contribuir a los gastos públicos. Los demás deben soportarlos progresivamente, según la extensión de su fortuna. ${ }^{51}$

Del artículo décimo cabe destacar que tanto la provisión de trabajo para los válidos como las ayudas sin contraprestación para los inválidos se entienden ya no como un medio para asistir a los pobres, sino como una forma de asegurar la subsistencia a todos los miembros de la sociedad. Recordemos que esta había sido justamente la crítica que Robespierre había hecho a la propuesta de Oudot, apenas dos días antes. La obligación de la sociedad de asegurar la subsistencia a todos los ciudadanos no es un deber de caridad hacia los necesitados, sino una exigencia de justicia. No es otra cosa, en definitiva, que la actualización, en el estado social, del derecho natural a la existencia.

50 Sobre estos dos principios, en particular, y sobre las Declaraciones de derechos durante la Revolución Francesa, en general, véase: Ricardo García Manrique, "Sentido y contenido de la Declaración de 1789 y textos posteriores", en Gregorio Peces-Barba, Eusebio Fernández y Rafael de Asís (dirs.), Historia de los Derechos Fundamentales. Tomo II. Volumen III, Dykinson, Madrid, 2001, pp. 217-394.

${ }^{51}$ Maximilien Robespierre, OEuvres de Maximilien Robespierre, op. cit., pp. 465-466. 
El artículo undécimo pone en relación el deber de la sociedad de asegurar la subsistencia a todos con el gasto público: los pobres, en la medida en que no se respete su derecho natural a la existencia, son los acreedores del cuerpo social, que está obligado a saldar esta deuda con ellos. La expresión "deuda" no es nueva: recordemos que el Comité de mendicidad hablaba ya de una deuda sagrada, y que el proyecto de Condorcet definía la asistencia justamente en esos términos. Lo que sí es distinto con respecto al artículo de Condorcet, así como al que finalmente será recogido en la Constitución del 93, es la precisión de quién tiene la obligación o la deuda con los pobres, con aquellos que no tienen los medios necesarios para vivir con dignidad. En el caso del texto de Robespierre, no se trata de una deuda genérica del conjunto de la sociedad, sino de aquellos que poseen lo superfluo, de los ricos, aunque después corresponda a la sociedad en su conjunto, a través de la ley, determinar la forma en que esta deuda debe ser saldada.

De este modo, el artículo undécimo sirve de nexo entre el décimo, en el que se reconoce el derecho de todos a disponer de los medios de subsistencia, y el duodécimo, en el que se establece la progresividad impositiva: los ricos, en la medida en que se han apropiado de una parte de la riqueza social mayor a lo que les corresponde por derecho, son quienes más deben contribuir a pagar a esos hambrientos acreedores a quienes no se les está garantizando su derecho natural a la existencia.

Estos tres artículos, puestos en relación con el conjunto del proyecto, son una buena sintesis de los principios que deben guiar, según Robespierre, el programa social de la naciente República. El derecho natural a la existencia debe ser asegurado a toda la población mediante la provisión pública o privada de trabajo, mediante la asistencia pública para aquellos incapaces de trabajar y, más generalmente, a través de una serie de leyes destinadas a limitar la propiedad y la riqueza superflua de los ricos.

\subsection{La Constitución de 1793}

Un Comité de salvación pública (Comité de salut public) había sido creado en abril para controlar al Consejo ejecutivo y hacer frente a la guerra. Originalmente estaba formado por nueve diputados, entre los que destacan Barère (de la Llanura) y Danton (montagnard). El 30 de mayo se unen al mismo cinco nuevos diputados, encargados de proseguir con la elaboración de la Constitución. La composición de esta comisión constitucional es una buena muestra de la pérdida de peso político de los girondinos en la víspera de la insurrección del 31 de mayo. La componen Hérault de Séchelles (montagnard próximo a Danton), Couthon, Saint-Just (ambos montagnards próximos a Robespierre), Ramel-Nogaret y Mathieu-Mirampal (ambos diputados de la Llanura y alejados de la Montaña). Tras la insurrección, es esta misma comisión (de cuyas deliberaciones se sabe poco) la que se encarga de elaborar la Constitución de 1793, que difiere notablemente del proyecto girondino. El nuevo texto ve la luz en menos de un mes: la Constitución se aprueba el 24 de junio, quedando en suspenso hasta el fin de la guerra. Se guarda simbólicamente en un arca de madera de cedro, a los pies de la presidencia de la Convención.

La Declaración de derechos que encabeza el texto tiene 35 artículos. E1 21 reconoce el derecho a la asistencia como una deuda sagrada de la sociedad, igual 
que lo hacian el proyecto de Condorcet y el girondino. A continuación, retoma esa distinción entre pobres válidos e inválidos presente en la Constitución de 1791, y que había desaparecido en esos dos proyectos de 1793:

XXI. La asistencia pública [secours publics] es una deuda sagrada. La sociedad debe la subsistencia a los ciudadanos desgraciados, sea procurándoles trabajo, sea asegurando los medios de existencia a aquellos que no están en condiciones de trabajar. 52

Existe una diferencia de tipo formal, de escasa importancia, con respecto a la Constitución de 1791: la asistencia se incluye entre los derechos del hombre y del ciudadano, frente a su anterior carácter de "disposición fundamental". Tampoco hay novedades relevantes en cuanto al contenido del derecho. Aunque la asistencia pública se entiende como una "deuda sagrada", se sigue centrando en una parte concreta de la población. En consecuencia, la provisión de trabajo para los válidos es, una vez más, una ayuda dirigida solamente a los más pobres. No se entiende, a diferencia de lo que sucedia con el proyecto de Robespierre, como la actualización del derecho natural que todo hombre tiene a una existencia digna.

\section{CONCLUSIÓN: LIBERTAD DE TRABAJO Y DERECHO A LA ASISTENCIA}

Espero que estas páginas hayan servido para explicar la forma en que se concibe el derecho a la asistencia pública durante la Revolución Francesa. La génesis de la Declaración de derechos de 1789, así como los trabajos del Comité de mendicidad, dependiente de la Asamblea nacional, creo que ayudan a delimitar el alcance que cabe atribuir a la séptima disposición fundamental de la Constitución de 1791. De la misma manera, me parece que los límites del artículo 21 de la Constitución de 1793 se entienden mejor si se atiende a las discusiones parlamentarias en torno a la asistencia que tienen lugar esa primavera. Tanto en 1791 como en 1793 no se reconoce finalmente el derecho a la asistencia, sino el deber de la sociedad de asistir. Además, y esto es lo más relevante, la asistencia pública no tiene un carácter general, sino que se concibe como una ayuda focalizada en los ciudadanos caídos en desgracia.

Ambos textos constitucionales son ambiguos con respecto a la amplitud de la asistencia que merecen los pobres válidos sin trabajo. Como ya hemos explicado, esta resulta inseparable de la nueva importancia que se asigna en la época a la libertad de trabajo. En primer lugar, los individuos tienen el derechodeber de ganarse la vida a través del trabajo. Pueden hacerlo, desde el momento en que se suprimen las corporaciones de oficios, en igualdad de condiciones con respecto a cualquier otro ciudadano. Solamente en caso de necesidad tienen derecho a la asistencia pública, acompañada, de nuevo, del deber de trabajar. El derecho universal a la subsistencia se concreta, asi, en dos derechos distintos: primero, la libertad de trabajo, que se concibe entonces como el instrumento más potente de integración y bienestar social; de forma subsidiaria, el derecho a la asistencia a través del trabajo.

52 Constitution du 24 juin 1793 (6 messidor an I): https://www.conseil-constitutionnel.fr/lesconstitutions-dans-1-histoire/constitution-du-24-juin-1793. 
Esta respuesta dual al problema de los pobres válidos sin trabajo encierra una tensión en su interior. A la nueva comunidad politica se le imponen dos deberes dificilmente conciliables. Por un lado, abstenerse de intervenir en el ámbito del trabajo. Por otro lado, establecer un sistema público de asistencia para los perjudicados por el nuevo escenario competitivo. Detrás de estos deberes hay dos ideas muy fuertes, que nacen al mismo tiempo. Por un lado, una sociedad móvil y abierta, en la que solamente el mérito individual debe permitir ascender en la escala social. Por otro lado, un Estado social que se ocupa del bienestar de los ciudadanos. Por mucho que este Estado providencia (todavia por construir) se conciba como un mecanismo que entra en funcionamiento solamente en caso de imperiosa y constatada necesidad, su existencia supone la aparición de una lógica de distribución de recursos que no casa bien con esa espontaneidad que supuestamente debe regir en el terreno de lo social. Como dice Castel, "implícitamente se hacian coexistir dos concepciones contradictorias del rol del Estado". 53

Esta combinación de libertad ilimitada y asistencia pública, de una posición liberal con otra estatista, se canaliza a través del lenguaje común de los derechos:

El sentido de la palabra 'derecho', cuando se refiere al socorro no es el mismo que cuando concierne al trabajo. En el primer caso, se trata de una deuda de la sociedad con el indigente. El Estado 'debe' (y quizá pueda) emplazar un sistema de socorro público, recaudar impuestos, reclutar personal, crear instituciones especiales, etcétera. No es lo mismo cuando se trata de 'procurar la subsistencia por el trabajo': el Estado se niega explícitamente a asumir la responsabilidad de asegurarle un trabajo a cada uno. 54

¿La clase propietaria utiliza el discurso de los derechos de una manera cínica desde el principio, para encubrir bajo un manto de libertad sus intereses particulares?

No hay mucho mérito en interpretar la historia retrospectivamente, corrigiéndola a la luz de lo que ocurrió a continuación. Mi interpretación es más bien que la ambigüedad constantemente subrayada a través del análisis de estas posiciones era una ambigüedad real, presente en los espíritus, porque estaba también en los hechos. Ésta es la razón por la cual, a una lectura cínica (la burguesía en ascenso lo manipuló todo en función de su interés), yo profiero otra, que permita reubicar este episodio revolucionario en el largo término e introduzca una mejor comprensión de las peripecias futuras de la cuestión social. 55

El discurso revolucionario sobre la asistencia a los pobres válidos, del que hoy es fácil percibir su ambigüedad, tiene en la época un componente utópico. Las élites revolucionarias abogan por la extensión de las fuerzas más dinámicas de la sociedad de finales del siglo XVIII, sin advertir -o sin ser capaces de anticipar - las contrapartidas sociales de esta extensión, que no son plenamente inteligibles en aquel momento. En cualquier caso, no faltan voces advirtiendo de la cara menos amable de la utopía. Marat en 1789, y Robespierre en 1793,

53 Robert Castel, Las metamorfosis de la cuestión social. Una crónica del salariado, Paidós, Buenos Aires, 1997, p. 193.

54 Robert Castel, Las metamorfosis de la cuestión social, pp. 196-197.

55 Robert Castel, Las metamorfosis de la cuestión social, p. 201. 
pretenden hacer compatible el desarrollo de la industria y del comercio con la garantía del derecho universal a la existencia. Ya no se trata de socorrer a los miserables, sino de que quienes disfrutan de lo superfluo salden su deuda con quienes carecen de lo necesario.

\section{BIBLIOGRAFÍA}

Baecque, Antoine (de); Schmale, Wolfgan y Vovelle, Michel (1988). L'An 1 des droits de l'homme. Mesnil-sur-l'Estrée: Presses du CNRS.

Bloch, Camille y Tuetey, Alexandre (1911). Procès-verbaux et rapports du Comité de mendicité de la constituante : 1790-1791. París: Imprimerie Nationale.

Boncerf, Pierre-François (1789). De la nécessité et des moyens d'occuper avantageusement tous les gros ouvriers. París: Badouin.

Castel, Robert (1997). Las metamorfosis de la cuestión social. Una crónica del salariado. Buenos Aires: Paidós.

Conchon, Anne (2011). "Les travaux publics comme ressource : les ateliers de charité dans les dernières décennies du XVIII siècle", Mélanges de l'École française de Rome - Italie et Méditerranée modernes et contemporaines, 123 (1): 173-180.

Dreyfus, Ferdinand (1905). L'Assistance sous la Législative et la Convention (17911795). Paris: Société Nouvelle de Librairie et d'Édition.

Duvergier, Jean-Baptiste. Collection complète des Lois, Décrets, Ordonnances, Réglemens et Avis du Conseil-d'État. Paris: A. Guyot et Scribe.

Fauré, Christine (1995). Las declaraciones de los derechos del hombre de 1789. Ciudad de México: Fondo de Cultura Económica.

García Manrique, Ricardo (2001), "Sentido y contenido de la Declaración de 1789 y textos posteriores", en Peces-Barba, Gregorio; Fernández, Eusebio y Asís, Rafael (de) (dirs.) (2001). Historia de los Derechos Fundamentales. Tomo II. Volumen III. Madrid: Dykinson, pp. 217-394.

Gauchet, Marcel (2010). La Révolution des droits de l’homme. Plessis-Trévise: Gallimard.

Gauthier, Florence (2014). Triomphe et mort de la Révolution des droits de l'homme et du citoyen (1789-1795-1802). París: Syllepse.

Jaume, Lucien (ed.) (1989). Les Déclarations des droits de l’homme. (Du Débat 1789-1793 au Préambule de 1946), con prefacio y notas del editor. París: Flammarion.

Malouët, Pierre-Victor (1789). Opinion de M. Malouët sur la Déclaration des Droits de l'Homme, dans la Séance du 2 Août. Sin lugar de edición ni editorial.

Malouët, Pierre-Victor (1875). "Motion d'ordre de M. Malouët pour la création de bureaux de secours, lors de la séance du 3 août 1789", en Archives Parlementaires de 1787 à 1860 - Première série (1787-1799) Tome VIII : du 5 mai 1789 au 15 septembre 1789. París: P. Dupont, pp. 337-339.

Marat, Jean-Paul (1789). Projet de déclaration des droits de l'homme et du citoyen, suivi d'un Plan de constitution juste, sage et libre. París: Buisson. 
Masméjan, Jean-Baptiste (2016). "Le comité de mendicité mandaté par la nation : vers une harmonisation de la politique d'assistance des valides (1790-1791)", Cahiers Jean Moulin, 2: 1-22.

Mavidal, Jérôme y Laurent, Émile. Archives parlementaires : de 1787 à 1860. Recueil complet des débats législatifs \& politiques des chambres françaises. Première série (1787 à 1799). París: Paul Dupont.

Olejniczak, William (1990). "Working the Body of the Poor: The 'Ateliers de Charité' in Late Eighteenth-Century France", Journal of Social History, 24 (1): 87-107.

Parturier, Louis (1897). L'Assistance à Paris sous l'Ancien Régime et pendant la Révolution. París: Champion.

Robespierre, Maximilien (1850). Déclaration des droits de l'homme et du citoyen présentée à la Convention nationale en 1793. París: Rey, Delavigne et Compagnie.

Robespierre, Maximilien (1958). OEuvres de Maximilien Robespierre. Tome IX: Discours (4ème Partie. Septembre 1792 - Juillet 1793), editado por la VI Section de l'École des Hautes Etudes y la Société des Études Robespierristes, a cargo de Marc Bouloiseau, Georges Lefebvre, Jean Dautry y Albert Soboul. Paris: Presses Universitaires de France.

Sewell, William H., Jr. (1992). Trabajo y revolución en Francia. El lenguaje del movimiento obrero desde el Antiguo Régimen hasta 1848, traducción de Enrique Gavilán. Madrid: Taurus.

Sieyes, Emmanuel-Joseph (1789). Préliminaire de la Constitution françoise. Reconnoissance et exposition raisonnée des Droits de l'Homme et du Citoyen. París: Baudouin.

Sieyes, Emmanuel-Joseph (1985). Écrits politiques, edición y presentación de Roberto Zapperi. Bruselas: Éditions des Archives Contemporaines.

Target, Guy-Jean-Baptiste (1789). Projet De Déclaration des Droits de l'Homme en Societé. Paris: Baudouin.

Enviado el (Submission Date): 06/04/2020

Aceptado el (Acceptance Date): 02/05/2020 